Case Report

\title{
A Case Report of Severe Hypokalemic Quadriparesis as the First Manifestation of Type I RTA in Primary Sjogren's Syndrome
}

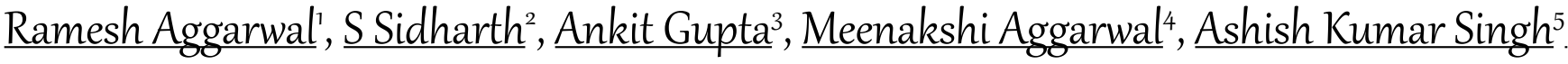 \\ ${ }^{1}$ Professor, ${ }^{2}$ Postgraduate Resident, ${ }^{3}$ Assistant Professor, ${ }^{5}$ Senior Resident, Department of Medicine, Lady Hardinge Medical \\ College, New Delhi, India. \\ ${ }^{4}$ Specialist \& Incharge, Microbiology Laboratory, Kalawati Saran Children Hospitals, LHMC, New Delhi, India. \\ DOI: https://doi.org/10.24321/2349.7181.202111
}

\section{I $\quad \mathbf{N} \quad \mathbf{F} \quad \mathbf{O}$}

\section{Corresponding Author:}

S Sidharth, Department of Medicine, Lady Hardinge Medical College, New Delhi, India.

E-mail Id:

drsidharth27@gmail.com

Orcid Id:

https://orcid.org/0000-0003-0455-9349

How to cite this article:

Aggarwal R, Sidharth S, Gupta A, Aggarwal M, Singh AK. A Case Report of Severe Hypokalemic Quadriparesis as the First Manifestation of Type 1 RTA in Primary Sjogren's Syndrome. J Adv Res Med. 2021;8(2):27-29.

Date of Submission: 2021-05-20

Date of Acceptance: 2021-06-28

\section{$\begin{array}{llllllll}\mathbf{A} & \mathbf{B} & \mathbf{S} & \mathbf{T} & \mathbf{R} & \mathbf{A} & \mathbf{C} & \mathbf{T}\end{array}$}

Primary Sjogren's syndrome is an autoimmune disorder primarily involving the exocrine glands but it can have a varied presentation. It can also present without classically described sicca symptoms. Onethird of the patients experience extra-glandular involvement in the form of nonspecific arthralgia, myalgia, arthritis, parenchymal involvement of renal parenchyma, lung, and rarely nerves. Renal involvement in primary Sjogren's can present with type 1 renal tubular acidosis (RTA) and is associated with a normal anion gap and hypokalemia. We, hereby, report a case of primary Sjogren's syndrome presenting with type 1 RTA with hypokalemic quadriparesis as the first presenting feature.

Keywords: Primary Sjogren's Syndrome, Type 1 Renal Tubular Acidosis, Periodic Quadriparesis, Hypokalemia

\section{Introduction}

Primary Sjogren's syndrome is a systemic autoimmune disease with a prevalence of $0.01 \%$ to more than $3 \%$ in epidemiological studies. ${ }^{1}$ It is characterised by lymphocytic infiltration of exocrine glands like lacrimal and salivary glands. Renal involvement occurs with interstitial nephritis manifesting as hyposthenuria, renal tubular acidosis with hypokalemia, nephrogenic diabetes insipidus etc. Type 1 renal tubular acidosis (RTA) is usually associated with the disease.

\section{Case Report}

A 27-year-old female presented to the emergency of a tertiary care hospital with the first episode of sudden onset flaccid quadriparesis of 2 hours duration. The patient had complaints of mild pain in the bilateral upper and lower limbs before the onset of weakness. The patient was lying supine on the couch when she noticed that she was unable to move her limbs completely along with weakness of neck and trunk. Sensations were preserved with normal bowel and bladder sensation. There were no complaints of neck pain, fever, loss of consciousness, trauma to spine and head, speech disturbances, and diminution of vision. Also, there were no complaints of preceding diarrhoea, joint pain, or oral ulcers. On examination, the patient was found conscious and oriented, with stable vitals, a pulse rate of $68 / \mathrm{min}$, and $\mathrm{BP}$ of $112 / 72 \mathrm{mmHg}$. Cranial nerve examination was normal and the power in bilateral 
upper and lower limbs across all the joints, neck flexors and trunk was $0 / 5$. Deep tendon reflex was +1 in bilateral biceps, triceps, knee and ankle with mute plantars. Sensory examination for pain, touch, temperature, proprioception, and vibration was within normal limits.

Arterial blood gas analysis was suggestive of normal anion gap metabolic acidosis with $\mathrm{pH}-7.249, \mathrm{HCO}_{3}-9.1 \mathrm{meq} / \mathrm{L}$, $\mathrm{pCO}_{2}-21 \mathrm{mmHg}, \mathrm{pO}_{2}-90 \mathrm{mmHg}$, anion gap $-12.9 \mathrm{mEq} / \mathrm{L}$ (8-16), chloride - $118 \mathrm{meq} / \mathrm{L}$, and lactate $-1.36 \mathrm{mmol} / \mathrm{L}$. Haemogram was done which showed the following values: $\mathrm{Hb}-10.9 \mathrm{~g} / \mathrm{dl}$, TLC - 9100, DLC-neutrophils - 82\%/ lymphocytes $-9 \%$, platelets $-2.37 \mathrm{~L} / \mathrm{mm}^{3}$, ESR - 39. Complete biochemical blood parameters were done which showed severe hypokalemia ( $1.7 \mathrm{meq} / \mathrm{L}$ ) and other reports were as follows: sodium - $138 \mathrm{meq} / \mathrm{L}$, calcium/phosphorus - 8.6/2.9 $\mathrm{mg} / \mathrm{dl}$, magnesium -2.1 meq/L, urea/creatinine - 30/0.9 $\mathrm{mg} / \mathrm{dl}, \mathrm{AST} / \mathrm{ALT}$ - 34/20 U/L, total protein - $7.1 \mathrm{~g} / \mathrm{dl}$, serum albumin - $3.8 \mathrm{~g} / \mathrm{dl}$, amylase - 43U/L, and INR - 1.03. ECG showed evidence of $U$ waves and nonspecific ST-segment changes were seen in severe hypokalemia. Thyroid function test and intact-PTH was normal. HIV, HBsAg, anti-HCV all were negative. Urine $\mathrm{pH}-7$, protein/glucose/cast/crystals/ $\mathrm{RBC} /$ pus cells - Nil. Urine anion gap $-2 \mathrm{mEq} / \mathrm{L}$ (positive), urine osmolal gap was $<150 \mathrm{mOsmol} / \mathrm{kg}$ which along with alkaline urine $\mathrm{pH}$ was suggestive of type 1 RTA. Urine calcium/ creatinine ratio was $1.23(<0.2)$ suggesting hypercalciuria seen in type 1 RTA. However, USG-KUB and Xray-KUB were normal without any evidence of nephrocalcinosis. Chest roentgenogram was normal. Autoimmune profileSS-A/Ro 60 antibody was strongly positive (+3), SS-A/Ro52-(+3), SS-B/La-(+1), RA factor positive, and anti-CCP was negative. On the basis of history and examination, acute onset flaccid hyporeflexic quadriparesis with intact sensation was evaluated as hypokalemic paralysis. Arterial blood gas analysis was suggestive of normal anion gap metabolic acidosis with hypokalemia thus favouring renal tubular acidosis. Urine studies proved it to be type 1 RTA. Considering the clinical scenario to ascertain the cause of type 1 RTA with hypokalemic paralysis, workup for Sjogren's syndrome was done and serology was strongly suggestive of the disease.

For objective evidence of glandular involvement in Sjogren's disease, Schirmer's I test with $<5 \mathrm{~mm}$ in $5 \mathrm{~min}$ was demonstrated to be positive with tear breakup time $<15 \mathrm{sec}$ (abnormal) in bilateral eyes. Histopathology of minor salivary gland showed focal lymphocytic sialadenitis with a focus score of $>1$. With objective evidence of 3 out of 4 criteria according to the revised international classification criteria for Sjogren's syndrome, the patient was diagnosed as a case of primary Sjogren's syndrome. ${ }^{2}$ Treatment involved oral potassium chloride along with intravenous potassium replacement with normalisation of serum potassium to $3.7 \mathrm{mEq} / \mathrm{L}$ in 12 hours of presentation.
Bicarbonate replacement of $50 \mathrm{mEq}$ was initially given intravenously followed by maintenance oral bicarbonate. After correction of hypokalemia and acidosis, $\mathrm{pH}$ improved to $7.401, \mathrm{pCO}_{2}$ to $32.6, \mathrm{pO}_{2}$ to $90, \mathrm{HCO}_{3}$ to $18 \mathrm{mEq} / \mathrm{L}$, chloride to $113 \mathrm{mEq} / \mathrm{L}$, and potassium to $4.6 \mathrm{mEq} / \mathrm{L}$. Quadriparesis of the patient improved with treatment in 24 hours with power returning to normal $5 / 5$ in bilateral upper and lower limbs across all the joints, neck flexors, and trunk.

\section{Discussion}

Type 1 renal tubular acidosis is a disorder of the distal nephron, which cannot lower the urine $\mathrm{pH}$ normally. ${ }^{3}$ Type 1 RTA can be inherited or acquired. Among acquired, autoimmune diseases like Sjogren's syndrome, sarcoidosis, and systemic lupus erythematosus are common. Type 1 RTA is associated with hypokalemia and a normal anion gap. In type 1 RTA, the urinary ammonium excretion is inappropriately low for the level of acidosis as the defect in acidification decreases ion trapping required for ammonia secretion. Hence urinary anion gap (UAG = urinary $(\mathrm{Na}+\mathrm{K})$ $\mathrm{Cl})$ is positive. ${ }^{4}$

The patient presented with hypokalemic paralysis (quadriparesis) due to RTA as the first and only manifestation of Sjögren's syndrome. Even though asymptomatic for sicca symptoms, the patient had strongly positive serology for Sjögren's syndrome. ${ }^{5}$ Similar cases were reported by Goroshi et al. where a case series of primary Sjogren's presenting as hypokalemic paralysis was made. ${ }^{6}$ Objective evidence of lacrimal gland and minor salivary gland along with the serology supported the diagnosis of primary Sjogren's syndrome after excluding the evidence of cause for secondary Sjögren's syndrome. The patient had a very good response to replacement with potassium and bicarbonate with power improving to $5 / 5$ in 24 hours of treatment.

\section{Conclusion}

This case will open a new window to the possibility of Sjögren's syndrome in a case of type 1 RTA with hypokalemic paralysis even without any classical subjective symptoms of glandular manifestation. The case was peculiar in its presentation as quadriparesis as the first symptom in Sjogren's syndrome. Such patients may also be monitored for the development of sicca symptoms in the future.

\section{Consent}

Informed consent was taken from the patient for case reporting and the identity has not been disclosed.

\section{Financial Support: None \\ Conflict of Interest: None}

\section{References}

1. Cornec D, Chiche L. Is primary Sjögren's syndrome an orphan disease? A critical appraisal of prevalence 
studies in Europe. Ann Rheum Dis. 2015 Mar;74(3):e25. [PubMed] [Google Scholar]

2. Vitali $C$, Bombardieri $S$, Jonsson $R$, Moutsopoulos HM, Alexander EL, Carsons SE, Daniels TE, Fox PC, Fox RI, Kassan SS, Pillemer SR, Talal N, Weisman MH; European Study Group on Classification Criteria for Sjögren's Syndrome. Classification criteria for Sjogren's syndrome: a revised version of the European criteria proposed by the American-European Consensus Group. Ann Rheum Dis. 2002;61:554-8. [PubMed]

3. Rodriguez Soriano J. Renal tubular acidosis: the clinical entity. J Am Soc Nephrol. 2002;13:2160-70. [PubMed] [Google Scholar]

4. Palkar AV, Pillai S, Rajadhyaksha GC. Hypokalemic quadriparesis in Sjogren syndrome. Indian J Nephrol. 2011;21:191-3. [PubMed] [Google Scholar]

5. Muthukrishnan J, Dawra S, Marwaha V, Narayanan CS. Sjögren's syndrome presenting as hypokalemic paralysis. Med J Armed Forces India. 2015;71(Suppl 1):S172-4. [PubMed] [Google Scholar]

6. Goroshi M, Khare S, Jamale T, Shah NS. Primary Sjogren's syndrome presenting as hypokalemic paralysis: A case series. J Postgrad Med. 2017;63:128-31. [PubMed] [Google Scholar] 